\begin{tabular}{c} 
International Journal of Engineering \& Technology, 7 (4) (2018) $4030-4034$ \\
International Journal of Engineering \& Technology \\
SPC \\
Website: $\begin{array}{c}\text { ww. sciencepubco.com/index.php/IJET } \\
\text { doi:10.14419/ijet. } v 7 \text { it.16470 } \\
\text { Research paper }\end{array}$ \\
\hline
\end{tabular}

\title{
Conversion of organic fraction of municipal solid waste into solid fuel via hydrothermal carbonization
}

\author{
Herlian Eriska Putra ${ }^{1,3}$ *, Kania Dewi ${ }^{1}$, Enri Damanhuri ${ }^{1}$, Ari Darmawan Pasek ${ }^{2}$ \\ ${ }^{1}$ Faculty of Civil and Environmental Engineering, Bandung Institute of Technology, Bandung 40132, Indonesia \\ ${ }^{2}$ Faculty of Mechanical and Aerospace Engineering, Bandung Institute of Technology, Bandung 40132 Indonesia \\ ${ }^{3}$ Research Unit for Clean Technology, Indonesian Institute of Sciences, Bandung 40135 Indonesia \\ *Corresponding author E-mail: herl007@ lipi.go.id
}

\begin{abstract}
Hydrothermal carbonization (HTC) is thermochemical process that can convert wet biomass into coal-like material. In this study, a series of HTC experiments was done. In the first stage targeted to obtain the process condition for mixture component. The process conditions comprised temperature, solid load, and holding time. Five typical components were used as representative pseudo-components of organic fraction of municipal solid waste. Each of substrates was carried out on the prototype HTC reactor. Process condition took place temperature at 190,210 and $230^{\circ} \mathrm{C}$, with a holding time (30 and 60 minutes) and feed to water ratio $(0.1,0,2,0.3)$. The result from first stage showed that the optimum process condition for mixture component were temperature $215{ }^{\circ} \mathrm{C}, 55$ minutes, and solid load 0.16 . The process conditions were applied for next stage. In the second stage, mixture component comprised $15 \%$ fruit peel, $10 \%$ food waste, $10 \%$ of office paper, 30\% leaves, and 35\% sawdust were used as feedstock. Model to determine process condition for mixture component and also to predict high heating value have been developed. The fuel characteristics and combustion behavior of HTC-derived hydrochars were evaluated. Hydrothermal carbonization of waste gave high heating value (HHV) with value of $20.24 \mathrm{MJ} / \mathrm{kg}$ higher than its raw $16.42 \mathrm{MJ} / \mathrm{kg}$.
\end{abstract}

Keywords: Hydro Char; Hydrothermal Carbonization; Municipal Solid Wastes; Organic Fraction; Process Conditions.

\section{Introduction}

In recent year, the demand for energy keep to increase continuously over the coming decades in order to fulfill the needs of growing populations. According to BP data, the increasing of Indonesia's energy consumption in 2016 has raised over the past 20 years [1]. No wonder, this caused by oil is still primary choice in energy sources, followed by coal and natural gas. Due to these are nonrenewable energy resource, it can be predicted with certainty that its supply will diminish.

In Indonesia, there is not only energy sector, but also solid waste still becomes a serious problem due to lack of final waste disposal facilities. As we know, municipal solid waste (MSW) composition is vary from one to another country. Several factors such as traditional habits, cultures, seasons, life style, population number and even Government policy are able to influence the characteristic of MSW. Specifically, more than $60 \%$ of solid waste composition in Indonesia is dominated by high organic fraction [2]. A lot of issues about waste problem and energy have encouraged public interest to replace fossil fuel into renewable.

In order to find alternative energy, the usage of MSW as solid fuel seems to be a good choice for urban community compare than composting the waste, which require a long time process. However, the directly use of it as fuel has many difficulties because of its heterogeneity, wet organic content, high moisture content, as well as low calorific value [3]. To improve its fuel characteristics, combusting technology such as incinerator, gasification or pyrolysis is required. Unfortunately, those technologies may not suitable to handle biomass with high moisture content [4], [5], like organic fraction of municipal solid wastes in Indonesia.
One of environmentally beneficial wet waste treatment process is hydrothermal carbonization (HTC). HTC can deal with wet biomass better than other thermochemical processes [6 - 8]. HTC is employed for producing hydrochar, a hydrophobic char with higher carbon content. Unlike biochar which is dominated by aromatics compound, hydrochar has slightly less stable structure which is dominated by alkyl moieties. This char is able to used not only as fuel but also as fertilizer, soil conditioner, catalyst, carbon material, chemicals and still more [9-11]. According to several researchers [9], [12-14], this non combustion process is usually performed at relatively low temperature $\left(<350^{\circ} \mathrm{C}\right)$, at autogenous pressure to ensure liquid water, and oxygen free condition. HTC reaction comprises a series of hydrolysis, dehydration, decarboxylation, condensation and polymerization reactions [6], [10], [15], [16]. During HTC, lignocellulose in organic fraction of MSW may be hydrolysed and depolymerized to monomers, oligomers, and also degradation compounds (sugar and organic acid). HTC is thermal process which employs subcritical water as a reaction medium for conversion of wet waste. Drying process for wet waste before applying HTC is not needed. The water that is contained in organic fraction can be used as solvent to pressurize the reaction medium. The use of high pressure in this process will cause energy requirement to heat water is smaller than to evaporate water within same amount in other thermal process.

Despite the advantage of HTC over other thermal processes with respect to handle MSW and to the ability of converting wet waste with no need of pre-drying the raw material [17], some of the past studies on HTC [18], [19] used MSW within low moisture content $(<40 \%)$. However, there is no report in open literature so far on HTC of organic fraction of municipal solid waste (OFMSW) which has low energy content and high moisture content $(>60 \%)$. In this 
study, HTC experiments were carried out under different holding time (HT), feed to water ratio (FWR), and temperature (T) conditions to study their effect on the hydrochar properties in terms of calorific value, proximate and ultimate analysis.

\section{Material and methods}

\subsection{Feedstock}

In Indonesia, specifically in Bandung city, the amount of MSW reached up to 1500 tons/day. It consists of $65 \%$ of organic fraction and $35 \%$ of inorganic fraction. Specifically, in Gumuruh district which covers residential, business and traditional market and knitting industry, the mean physical composition of MSW that used in this work is presented in Table 1, which was collected during dry season. Only organic fraction was utilized in carbonization process.

Table 1: Physical composition of MSW

\begin{tabular}{lll}
\hline Type & Component & Percentage $(\%)$ \\
\hline \multirow{3}{*}{ Organic } & Food waste & 34.61 \\
& Paper & 9.25 \\
& Wood waste & 18.6 \\
Non organic & Textile & 9.06 \\
& Rubber & 0.59 \\
& Plastic & 15.65 \\
& Others & 12.24 \\
\hline
\end{tabular}

According to Table 1, Albizia chinensis sawdust (ACS) were representative of wood waste, which were locally purchased. An 80 grammages (gms) of printing paper (PP) were representative of paper, which were collected at office. Rice with chicken bone (RCB), Musa spp banana peel (FP), Mangifera indica leaves (ML) were representative of food residue, which were collected from the cafeteria in our University. All feedstock were representatives of pseudo-organic fraction in MSW. Approximate size of it, in all dimensions, is $<1 \mathrm{~mm}$. Feedstock were air-dried prior to use in the carbonization experiments. Its chemical properties were given in Table 2.

Table 2: Chemical Properties of Feedstock

\begin{tabular}{llllll}
\hline Parameters (\%) & \multicolumn{5}{c}{ Feedstock } \\
\hline & ACS & FP & RCB & ML & PP \\
Moisture & 14.9 & 3.2 & 12 & 6.5 & 6.4 \\
Ash & 3.2 & 8.9 & 2.2 & 10.3 & 12.8 \\
Volatile & 83.2 & 71.8 & 87.6 & 75.5 & 81.2 \\
Fixed Carbon & 13.6 & 19.3 & 10.2 & 14.2 & 6.0 \\
Carbon & 52.5 & 50.0 & 39.9 & 42.8 & 39.7 \\
Hydrogen & 6.0 & 6.2 & 5.8 & 5.0 & 5.3 \\
Nitrogen & 0.2 & 1.6 & 4.3 & 1.8 & 0.2 \\
Oxygen & 42.3 & 31.3 & 41.3 & 37.2 & 54.9 \\
Sulfur & 0.0 & 0.2 & 0.3 & 6.1 & 0.1 \\
HHV (MJ/kg) & 18.8 & 16.7 & 18.0 & 18.8 & 14.5 \\
\hline
\end{tabular}

\subsection{Experimental procedure}

HTC process of OFMSW was carried out using a stainless steel stirred reactor. It was equipped with $2 \mathrm{~kW}$ heating mantle. A series of HTC experiments was done. In the first step targeted to obtain the process condition for mixture component. For this purposes, each of substrate $(50 \mathrm{~g})$ was dispersed in distilled water with ratio (feed to water ratio, FWR) 0.1, 0.2, 0.33 and blended for several minutes. Mixer was set $32 \mathrm{MHz}$ The mixture was then loaded into the reactor. The cover was put in place, checking that the reactor was air tight. Nitrogen gas was passed through the reactor for 5-10 min to ensure oxygen free in the system. To analyse the effect of operating condition on feedstock, the experiment was performed at the different holding time (HT) (30 and 60 minutes), and temperature $(\mathrm{T})\left(190,210,230^{\circ} \mathrm{C}\right)$ and setup as figure 1 below.

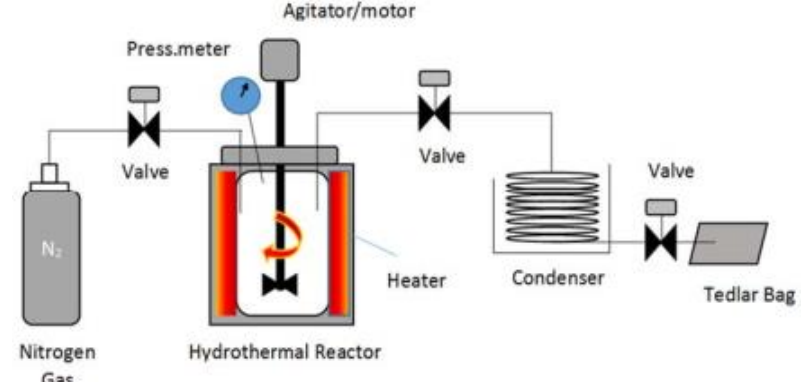

Fig. 1: Schematic of HTC Apparatus.

\subsection{Analysis}

Proximate analysis, covers determination of ash content, volatile matter, and fixed carbon, was measured using Leco TGA-601. Ultimate analysis (carbon $(\mathrm{C})$, hydrogen $(\mathrm{H})$, oxygen $(\mathrm{O})$, nitrogen $(\mathrm{N})$, sulfur (S)) was determined by using Elementar Vario Macro. HHV were measured using bomb calorimeter. All of these analyses were under supervised by Research and Development Center of Mineral and Coal Technology. Mass yield (MHY), energy densification ratio (EDR), and energy yield (EY) are parameters that were calculated in the study and are expressed as:

$$
\begin{aligned}
& \mathrm{MHY}=\frac{\text { mass of dried hydrochar }}{\text { mass of fried feedstock }} \times 100 \% \\
& \mathrm{EDR}=\frac{\text { HHV of hydrochar }}{\text { HHV of raw feedstock }} \\
& \mathrm{EY}=\mathrm{MHY} \times \mathrm{EDR}
\end{aligned}
$$

Where, MHY is mass hydrochar yield, HHV is high heating value, EDR is energy densification ratio, and EY is energy yield.

\section{Results}

\subsection{Effect of temperature, feed to water ratio, and holding time on HTC of OFMSW}

In this first step of HTC experiment, the goal was to obtain the process condition for mixture component. Results from studying the effect of three process condition T, HT, and FWR on hydrochar yield, energy yield, and HHV are reported. All the experiment in this investigation were conducted at autogenous pressure, adopted from our previous study [20-21]. This experiment data was collected twice to generate average value.

Hydrochar yield is one of main indicator for biomass hydrothermal carbonization process. Therefore, it is necessary to investigate the effect of process condition on hydochar yield from HTC of each feedstock. Hydrochar yield is determined according Eq. (1). Figure 2 shows results from this investigation. From Figure 2 the hydrochar yield decreases with increasing temperature, time, and feed to water ratio. When the temperature is elevated from 190 to $230{ }^{\circ} \mathrm{C}$, the hydrochar yield decreased vary from 68.1 to $60.8 \%$ for ACS, 52.3 to $32.5 \%$ for PP, 64.2 to $57.8 \%$ for FP, 63.2 to $51.7 \%$ for ML, and 62.4 to $41.3 \%$ for RCB.

As can be seen in Fig 2, feed to water ratio and holding time influence hydrochar yield. As expected, there is almost no difference between the hydrochar yield produced at 30 minutes and 60 minutes using the same FWR. This suggests that the solid load that used also determines the role of solvent. If the water ratio is used a lot and soak the entire surface of the biomass, then certainly the biomass decomposition reaction occurs perfectly. Conversely, if the water ratio is used a little, only a partially submerged surface of the biomass. As a result, decomposition occurs partly, but the resulting solid is high. In addition, the effects are more significant for biomass with cellulose and hemicellulose content are decomposed easily compare to biomass with high lignin content during hydrothermal carbonization. At temperature of hydrolysis between 160-180 
${ }^{\circ} \mathrm{C}$, more than $80 \%$ hemicellulose starts to be decomposed [22]. Unlike hemicellulose and cellulose, no more than $10 \%$ of lignin start to be decomposed at below $250{ }^{\circ} \mathrm{C}$ [22-23]. From Table 3, only ACS has higher lignin content.

Table 3: Lignocellulose Analysis of Feedstock

\begin{tabular}{lccccc}
\multicolumn{7}{c}{ Table 3: Lignocellulose Analysis of Feedstock } \\
Sample & $\begin{array}{c}\text { Percentage } \\
\text { Cellu- } \\
\text { lose }\end{array}$ & $\begin{array}{l}\text { Hemi- } \\
\text { cellu- } \\
\text { lose }\end{array}$ & $\begin{array}{l}\text { Lig- } \\
\text { nin }\end{array}$ & $\begin{array}{l}\text { Ex- } \\
\text { tract } \\
\text { ive }\end{array}$ & Total \\
\hline Albizi chinensis & 45.5 & 18.3 & 32.9 & 1.9 & 98.6 \\
Musa sp peel & 40.29 & 25.05 & 9.27 & 22.5 & 97.11 \\
Rice chicken bone & 27.2 & 43.21 & 0 & 2.3 & 72.71 \\
Printing paper & 98 & 0 & 0 & 0.8 & 98.8 \\
Mangifera leaves & 44.51 & 18.12 & 30.11 & 2.7 & 95.44 \\
\hline
\end{tabular}

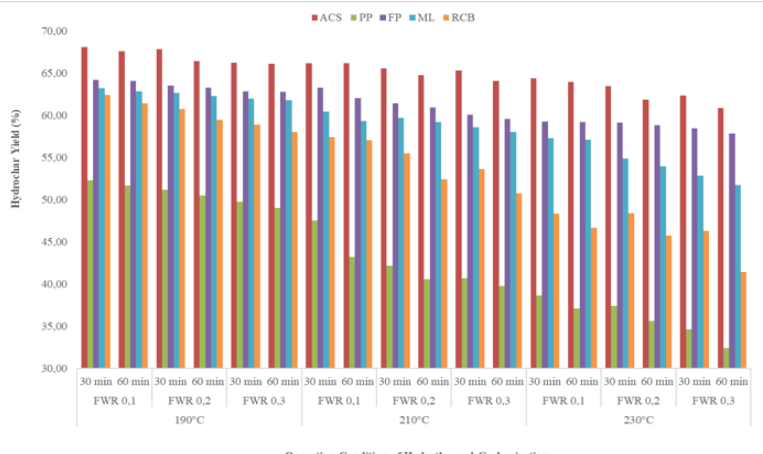

Fig. 2: Effect of Temperature, Feed to Water, and Holding Time on Hydrochar Yield.

Another important indicator of HTC of OFMSW is energy yield, $\mathrm{EY}$, which indicates how much energy leftover in the solid. It can be calculated by using Eq. (2) and Eq. (3). Figure 3 showed the calculated values of EY during the HTC process. In generally, it can be observed that for all feedstock except ACS, the energy yield constantly reduces with increasing temperature, holding time, and even feed to water ratio. ACS is different probably because of lignin content is the highest among other feedstock.

In the Fig. 4 also gives data about high heating value of feedstock and hydrochar. HHV increases with either increasing temperature, feed to water ratio, and holding time. Temperature gives more influence to increase HHV. The results suggested that the hydrothermal treatment of OFMSW to solid fuel give maximum high heating value (HHV) with value of 24.55, 21.24, 20.09, 24.22, and 22.70 $\mathrm{MJ} / \mathrm{kg}$ for ACS, PP, FP, ML, RCB, respectively. As a consequence of increasing HHV, energy densification also increases automatically. During HTC, oxygen and hydrogen content decreases while carbon content increase. Consequently, both $\mathrm{O} / \mathrm{C}$ and $\mathrm{H} / \mathrm{C}$ ratio of hydrochar is smaller than raw material, as can be seen in Figure 5. With smaller $\mathrm{O} / \mathrm{C}$ and $\mathrm{H} / \mathrm{C}$ ratio, hydrochar becomes coal-like material.

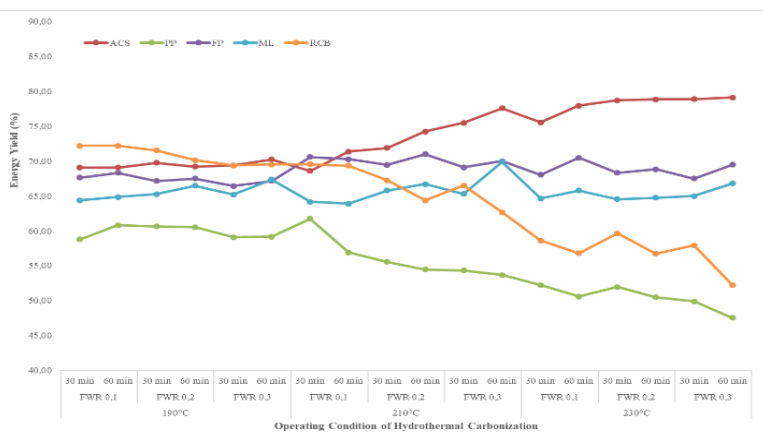

Fig. 3: Effect of Temperature, Feed to Water, and Holding Time on Energy Yield.

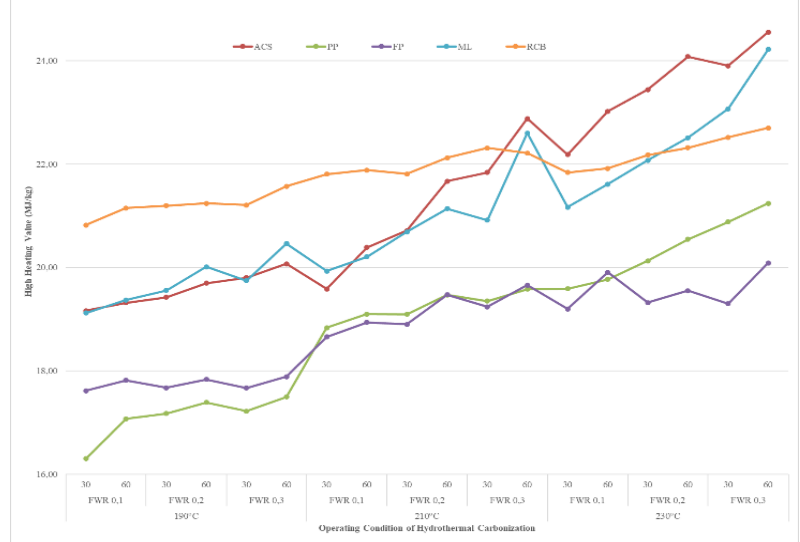

Fig. 4: Effect of Temperature, Feed to Water, and Holding Time on High Heating Value.

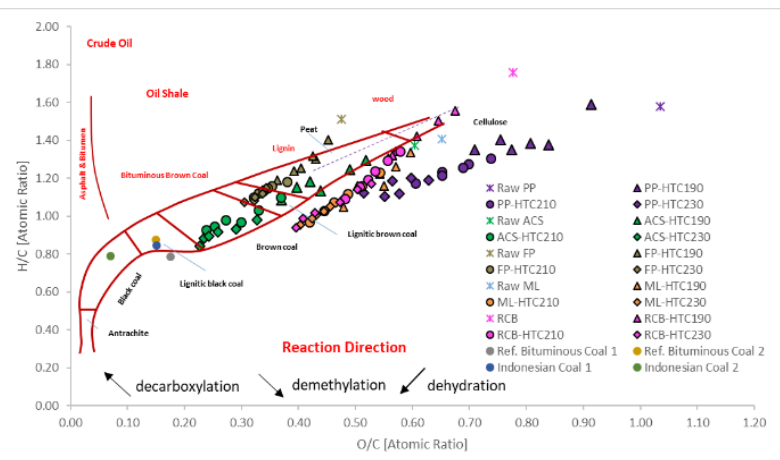

Fig. 5: The Van Krevelen Diagram.

\subsection{Determination of HTC process condition for mixture com- ponent}

The second step was used for HTC of mixture component (see Table 4). If HTC is considered closed system, the composition of the mixture can be described by giving the mass or the number of moles of each component present. So, the relative amounts of the components present in the mixture also can be described in terms of mass fraction.

Table 4: The Mean Physical Composition of MSW in Gumuruh, Bandung

\begin{tabular}{lll}
\hline Organic Fraction & $\begin{array}{l}\text { Sample } \\
\text { Composition }\end{array}$ & $\begin{array}{l}\text { Mass Fraction } \\
\text { (Total =1) }\end{array}$ \\
\hline & fruit peel & 0.15 \\
Food waste & rice with bone & 0.10 \\
& leaves & 0.30 \\
Paper & paper & 0.10 \\
Wood & sawdust & 0.35 \\
\hline
\end{tabular}

By adopting Amagat model, the process condition of mixture was determined. The underlying assumption of the Amagat model is that each mixture component behaves as an ideal gas as if it existed separately at temperature of the mixture. Thus, in terms of mass fraction, the partial temperature of each component i can be expressed as,

$T_{\text {mix }}=\sum_{i=1}^{n} T_{i} x_{i}$

where $T_{\text {mix }}$ is temperature of mixture component, $T_{i}$ is temperature of component $\mathrm{i}$ which gives high energy yield, $\mathrm{x}$ is mass fraction of component $\mathrm{i}$. By using the similar approaches, then for the parameters of feed to water ratio and holding time can be expressed as follows:

$F W R_{\text {mix }}=\sum_{i=1}^{n} F W R_{i} x_{i}$

$t_{\text {mix }}=\sum_{i=1}^{n} H T_{i} x_{i}$ 
where $\mathrm{FWR}_{\text {mix }}$ is feed to water ratio of mixture component, $\mathrm{FWR}_{\mathrm{i}}$ is feed to water ratio of $i$ which gives high energy yield, $t_{\text {mix }}$ is holding time of mixture component, $t_{i}$ is holding time of component $i$ which gives high energy yield, $x_{i}$ is mass fraction of component $i$. As mention before, optimum process condition of mixture component was determined by taking process condition which gives the best energy yield for each feedstock. Summary of equation derived from mass fraction (Table 3) and energy yield (Fig. 3) for each feedstock by using Eq. (4-6) express as follows:

$$
\begin{aligned}
& T_{\text {mix }}=230 x_{1}+210 x_{2}+210 x_{3}+210 x_{4}+190 x_{5} \\
& F W R_{\text {mix }}=0.1 x_{1}+0.3 x_{2}+0.2 x_{3}+0.1 x_{4}+0.3 x_{5} \\
& t_{\text {mix }}=60 x_{1}+30 x_{2}+60 x_{3}+60 x_{4}+30 x_{5}
\end{aligned}
$$

Where $\mathrm{x}_{1}, \mathrm{x}_{2}, \mathrm{x}_{3}, \mathrm{x}_{4}$, and $\mathrm{x}_{5}$ are mass fractions of ACS, PP, FP, ML, and $\mathrm{RCB}$ respectively. After substitute mass fraction (Table 3) into Eq. (7-9), so the process condition for mixture component are temperature $215{ }^{\circ} \mathrm{C}$, feed to water ratio at 0.16 , and holding time at 55 minutes. Results clearly illustrated that hydrothermal carbonization of waste gave high heating value (HHV) with value of $20.24 \mathrm{MJ} / \mathrm{kg}$ higher than its raw $16.42 \mathrm{MJ} / \mathrm{kg}$.

Validation of process condition for mixture component was done by comparing high heating value that was resulted from this mode with high heating value that resulted from HTC process at the same temperature (Figure 6). The high heating value (HHV) at the optimum temperature itself was calculated with the equation:

$$
H H V_{\text {mix }}=\sum_{i=1}^{n} H H V_{i} x_{i}
$$

Where $\mathrm{HHV}_{\text {mix }}$ is high heating value of mixture component, $\mathrm{HHV}_{\mathrm{i}}$ is high heating value of component $i$.

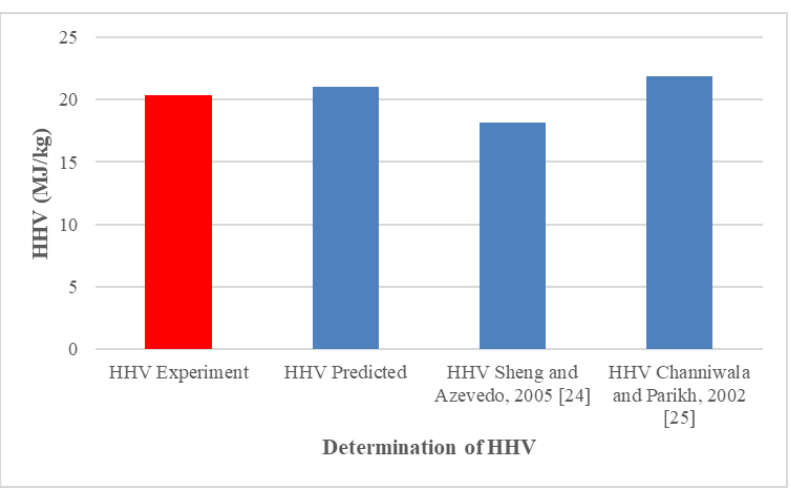

Fig. 6: Comparing HHV Predict vs Actual.

From Fig. 6, as can be seen that there is no significantly different between predicted model of HHV and actual HHV collected by experiment.

\section{Conclusion}

The results, both in terms of hydrochar yield, energy yield, and high heating value, showed that HTC represents an effective way to obtain a solid fuel with $\mathrm{O} / \mathrm{C}$ and $\mathrm{H} / \mathrm{C}$ characteristics quite similar with coal. The resulted showed that increasing reaction temperature, feed to water ratio and holding time during hydrothermal carbonization tend to increasing carbon content. The most significant parameter to improve energy yield is temperature. Biomass with contains more cellulose and hemicellulose is easier to decompose than lignin during hydrothermal carbonization. It also explains the reason of the HHV and carbon content increase of the most of feedstock after the hydrothermal treatment whose major component is cellulose. By adopting Amagat model, a model to predict HHV for mixture component has been developed. HHV of mixture component of OFMSW is $21.1 \mathrm{MJ} / \mathrm{kg}$, close to HHV from experiment $20.4 \mathrm{MJ} / \mathrm{kg}$.

\section{Acknowledgement}

The authors acknowledge Research and Development Center of Mineral and Coal Technology (Tekmira) for the support of his research. The author is Indonesia Endowment Fund for Education (LPDP) scholar. The works are financially supported by the Indonesian government through Ministry of Finance, Ministry of Research and Technology and Higher Education, and Bandung Institute of Technology.

\section{References}

[1] BP Statistical Review of World Energy, Indonesia Insights, From BP Publication (June 2017). https://www.bp.com/content/dam/bp/en/corporate/pdf/energy-economics/statistical-review2017/bp-statistical-review-of-world-energy-2017-indonesia-insights.pdf (accessed January 10, 2018)

[2] Indonesia Domestic Solid Waste Statistics, Ministry of Environment, 2008. https://www.scribd.com/document/254770564/Statistik-Persampahan-Indonesia-2008 (accessed November 21, 2017)

[3] Lin Y, Ma X, Peng X \&Yu Z (2017), forecasting the byproducts generated by hydrothermal carbonisation of municipal solid wastes. Waste Management \& Research 35, $92 \quad-\quad 100$ https://doi.org/10.1177/0734242X16678063.

[4] Hrncic MK, Kravanja G \& Knez Z (2016), hydrothermal treatment of biomass for energy and chemicals. Energy 116(2), 1312-1322. https://doi.org/10.1016/j.energy.2016.06.148.

[5] Lu L, Namioka T \& Yoshikawa K (2011), Effects of hydrothermal treatment on characteristics and combustion behaviors of municipal solid wastes. Applied Energy 88, 3659 - 3664 https://doi.org/10.1016/j.apenergy.2011.04.022.

[6] Funke,A \& Ziegler F (2010), Hydrothermal Carbonization of Biomass: A Summary and Discussion of Chemical Mechanisms for Process Engineering. Biofuels Bioproducts \& Biorefining-Biofpr 4, 160 - 177. https://doi.org/10.1002/bbb.198

[7] Libra JA, Ro KS, Kammann C, Funke A, Berge ND, Neubauer Y, Titirici MM, Fühner C, Bens O, Kern J \& Emmerich KH (2011), Hydrothermal carbonization of biomass residuals: a comparative review of the chemistry, processes and applications of wet and dry pyrolysis. Biofuels 2(1), 89 - 124. https://doi.org/10.4155/bfs.10.81.

[8] Ramke HG, Blöse D, Lehmann HJ \& Fetting J (2009), Hydrothermal carbonization of organic wastes. Twelfth International Waste Management and Landfill Symposium Proceedings. CISA Publisher.

[9] Mumme J, Eckervogt L, Pielert J, Diakité M, Rupp F \& Kern J (2011), hydrothermal carbonization of anaerobically digested maize silage. Bioresource technology 102(19), 9255 - 9260. https://doi.org/10.1016/j.biortech.2011.06.099.

[10] Sevilla M \& Fuertes AB (2009), the production of carbon materials by hydrothermal carbonization of cellulose. Carbon 47, 281-2289. https://doi.org/10.1016/j.carbon.2009.04.026.

[11] Yoshida T \& Antal MJ (2011), Carbonization for Terra Preta Aplications. Energy \& Fuels 23, 5454-5459. https://doi.org/10.1021/ef900610k.

[12] Zhang J, Lin Q \& Zhao X (2014), the hydrochar characters of municipal sewage sludge under different hydrothermal temperatures and durations. Journal of Integrative Agriculture 13(3), 471-482. https://doi.org/10.1016/S2095-3119(13)60702-9.

[13] Lu X, Jordan B \& Berge ND (2012), Thermal Conversion of Municipal Solid Waste via Hydrothermal Carbonization: Comparison of Carbonization Products to Products from Current Waste Management Techniques. Waste Management 32(7), 1353 - 1365 https://doi.org/10.1016/j.wasman.2012.02.012.

[14] Runge T, Wipperfurth P \& Zhang C (2013), Improving biomass combustion quality using a liquid hot water treatment. Biofuels 4, 73 - 83. https://doi.org/10.4155/bfs. 12.70

[15] Sevilla M \& Fuertes AB (2009), Chemical and structural properties of carbonaceous products obtained by hydrothermal carbonization of saccharides. Chem. Eur. J. 15, 4195-4203. https://doi.org/10.1002/chem.200802097.

[16] Titirici MM, Thomas A, Yu S-H, Müller J \& Antonietti M (2007), A Direct Synthesis of Mesoporous Carbons with Bicontinuous Pore Morphology from Crude Plant Material by Hydrothermal Carbonization. Chemistry of Materials 19(17), $4205-4212$. https://doi.org/10.1021/cm0707408

[17] Schneider D, Escala M, Supawittayayothin K, \& Tippayawong N (2011), Characterization of biochar from hydrothermal carbonization 
of bamboo. International Journal of Energy and Environment 2(4), 647-652.

[18] Muthuraman M, Namioka T \& Yoshikawa K (2010), Characteristics of co-combustion and kinetic study on hydrothermally treated municipal solid waste with different rank coals: A thermogravimetric analysis. Applied Energy 87, 141-148. https://doi.org/10.1016/j.apenergy.2009.08.004

[19] Prawisudha P, Namioka T \& Yoshikawa K (2012), Coal alternative fuel production from municipal solid wastes employing hydrothermal treatment. Applied Energy 90, 298-304. https://doi.org/10.1016/j.apenergy.2011.03.021.

[20] Eriska H, Dewi K, Pasek AD, \& Damanhuri E (2016), Hydrotherma Carbonization of Biomass Waste by Using a Stirred Reactor: An Initial Experimental Results. Reaktor 16(4), 212-217. https://doi.org/10.14710/reaktor.16.4.212-217.

[21] Putra HE, Dewi K, Pasek AD \& Damanhuri E (2018), hydrothermal carbonization of biomass waste under low temperature condition. MATEC Web of Conferences 154, 01025 https://doi.org/10.1051/matecconf/201815401025.

[22] Bobleter O (1994), hydrothermal degradation of polymers derived from plants. Progress in polymer science 19(5), 797-841. https://doi.org/10.1016/0079-6700(94)90033-7.

[23] Yuliansyah AT, Hirajima T, Kumagai S \& Sasaki K (2010), Production of solid biofuel from agricultural wastes of the palm oil industry by hydrothermal treatment. Waste and biomass valorization 1(4) 395-405. https://doi.org/10.1007/s12649-010-9045-3.

[24] Sheng C \& Azevedo JLT (2005), Estimating the higher heating value of biomass from basic analysis data. Biomass and Bioenergy 28(5), 499-507. https://doi.org/10.1016/j.biombioe.2004.11.008.

[25] Channiwala SA \& Parikh PP (2002), a unified correlation for estimating HHV of solid, liquid and gaseous fuels. Fuel 81(8), 10511063. https://doi.org/10.1016/S0016-2361(01)00131-4 